\title{
Lógica y génesis de un pronunciamiento: “los jesuitas se ponen verdes"
}

\section{Leandro Sequeiros SAN Román S.I. ${ }^{2}$}

No, no es ninguna de las dos cosas. $\mathrm{Ni}$ los jesuitas se dedican a insultarse. $\mathrm{Ni}$ se han apuntado a un partido ecologista. Es más sencillo: la Compañía de Jesús, consciente de las implicaciones que tiene para la reconciliación de los humanos entre sí y con la naturaleza, han hecho público un extenso documento de amplio alcance: Sanar un mundo herido. Ha sido dado a conocer a través del boletín Promotio lustitiae, del Secretariado de la Compañía para la Justicia Social y la Ecología (Roma, 2011).

La Ecología es una disciplina biológica bien formalizada que estudia las interacciones de los sistemas, tanto naturales como sociales. Por extensión del término, se suele utilizar de forma generosa para referirse a la incidencia social de los desajustes ambientales. Pero todavía esta descripción es demasiado vaga. Se suelen diferenciar distintos patrones para enfocar la ecología social:

1) El primero de ellos, es el patrón tecnocrático. Supone que el objetivo de esta disciplina es dar a conocer la existencia de riesgos y desajustes ambientales, consecuencia inevitable del desarrollo técnico e industrial, y que existen tecnologías correctoras de estos desajustes. No cuestiona el modelo de desarrollo global del planeta. Las políticas neoliberales suelen defender este modelo.

2) El segundo patrón es el cientificista. Sus seguidores consideran que la ecología es estrictamente una disciplina científica de rango universitario con su propia racionalidad y métodos. Para esta postura, las alusiones a las implicaciones sociales y políticas es simplemente una contaminación ideológica ajena a la ciencia que es necesario evitar por razones de rigor metodológico.

3) El patrón catastrofista de algunas orientaciones de la ecología está cercano al "ecologismo" barato de algunos grupos. Supone que todo desarrollo científico y tecnológico es pernicioso para la "naturaleza". Sus seguidores consideran la naturaleza al modo aristotélico, como un sistema rígido, inmutable y ordenado,

' Cátedra Ciencia-Tecnología-Religión, Universidad Pontificia Comillas (Madrid). Córdoba. 
casi sagrado, sin capacidad de comportamiento ecológico adaptativo y que por ello no debe modificarse nada.

4) El patrón sostenible, es el que defienden los grupos socialdemócratas. Originado por el Informe Brundtland (1984) supone que la naturaleza es flexible, pero tiene límites de resistencia. Por ello, defienden que se puede modificar la naturaleza hasta las fronteras de la sustentabilidad. Es el patrón vigente que se consolida en la Cumbre de Río (1992) y llega hasta hoy en los programas políticos. Ha sido muy criticado desde posturas más sociales.

5) El patrón político: reduce todo el contenido de la problemática del Medio ambiente a una cuestión de la política de las altas esferas, dejando en mano de los poderes públicos, a los técnicos ambientales, y en definitiva a las multinacionales la solución a los problemas del planeta. Así, la ideología subyacente al grupo The Science \& Environmental Policy Project (http://www.sepp.org/l, tras la que existen grandes intereses de multinacionales contaminantes, y que pretende demostrar que no hay peligro de cambio climático antrópico, es típica de esta postura.

6) El patrón ecosolidario, acepta la existencia de un mundo de mercado global, pero que este sistema lleva a un abismo de desigualdad entre los seres humanos. Defiende la potenciación de una conciencia ética para un cambio de actitudes, valores y comportamientos con respecto al planeta Tierra. Parte del esfuerzo por conocer y comprender los desajustes provocados por el impacto humano sobre la biosfera. Anima a desarrollar actitudes de comprensión global del ecosistema y a construir actitudes que lleven a colaborar en programas de ética ambiental. Cree que se deben armonizar los aspectos ambientales, con los del desarrollo humano y la salvaguarda de los derechos humanos en un mundo progresivamente más escindido en dos bloques: el más pequeño en población pero más poderoso en economía y poder (el primer mundo) y el más numeroso en población pero empobrecido por el modelo de desarrollo (el Tercer Mundo).

Si en el documento de la Compañía de Jesús de 1999, Un mundo roto, se encontraban mezclados estos seis patrones, en el documento Sanar un mundo herido, se hace una clara opción por el patrón ecosolidario. Ya en los documentos de la $35^{a}$ Congregación general de la Compañía de Jesús (Roma, enero-marzo 2008), sobre todo en los números 31 al 36 del decreto 3, Desafíos de nuestra Misión hoy:

Para escuchar, una vez más, el llamamiento a promover relaciones justas con la creación, hemos sino movidos por el clamor de los que sufren las consecuencias de la destrucción 
medioambiental, por los numerosos postulados recibidos y por las recientes enseñanzas del Santo Padre y de muchas Conferencias episcopales sobre este asunto (34).

El documento insiste que una parte de la misión de la Compañía de Jesús consiste en responder a los desafíos ecológicos o medioambientales para "apreciar más profundamente nuestra alianza con la creación" (decreto $3, n^{\circ} 36$ ). El cuidado del medio ambiente "afecta al centro de nuestra fe en Dios y nuestro amor a Él" (decreto $3, n^{\circ} 32$ ).

Por eso, terminada la Congregación general se constituyó una comisión de trabajo ("Task Force"),

convocada conjuntamente por el Secretario para la Justicia Social y Ecología y por el de Educación Superior. Estaba formada por cinco jesuitas y una persona laica escogidos en representación de las seis conferencias de la Compañía. A la Task Force se le encomendó la tarea de redactar para el Padre General un informe sobre "la misión jesuita y la ecología". Y se le instó a que, inspirándose en lo dicho al respecto por la lglesia y la Compañía y teniendo presentes las iniciativas ya emprendidas por las distintas conferencias y provincias, presentara recomendaciones prácticas para favorecer la integración de la preocupación por la ecología en todos nuestros ministerios. Igualmente se le pidió que, en la elaboración de tales recomendaciones, adoptara un punto de vista intersectorial o interdisciplinar, acentuando los aspectos globales e internacionales de las distintas cuestiones y centrándose en temas y metodologías en las que la Compañía pueda hacer uso de sus capacidades (Sanar un Mundo herido, $n^{\circ} 3$ )

La "Task Force" celebró una última reunión en Roma del 15 al 20 de noviembre de 2010 para concluir el informe. Ésta es la "visión" (el presupuesto, lo que llamaríamos en terminología de Ignacio. El "principio y fundamento":

Profundizar en nuestra experiencia de fe en el don de la vida que procede de un Dios creador, nos demanda un cambio en la manera de responder a la urgente tarea de la reconciliación con la creación. La creación, don del Dios de la vida, se ha convertido hoy en un bien material, explotable y comercializable. Nuestro mundo, lleno de paradojas, nos confunde y acusa, aunque al mismo tiempo presenta signos alentadores. Hay miedo, convulsión, sufrimiento, desesperación, pero también expresiones de esperanza y confianza. Todos somos responsables, aunque unos más que otros; todos sufrimos las consecuencias, pero también unos más que otros. Demasiados seres humanos, apoyados en el desarrollo tecnológico y espoleados por la codicia, continúan dominando y expoliando la naturaleza en el avance hacia el "progreso»; son pocos, demasiado pocos, los que toman en consideración las consecuencias de sus acciones. (Sanar un Mundo herido, $n^{\circ} 5$ ) 